\title{
Mental Wellness through Culture: An Examination of Youth Suicide Rates in Canada's Aboriginal Communities and Recommendations for Public Policy
}

\author{
MARLA TURNER \\ University of Victoria \\ craigmarla2@yahoo.ca
}

\begin{abstract}
This paper recognizes the high rate of Aboriginal youth suicide in Canada and the need for an intervention strategy. According to statistics, the high rate of suicide cannot be applied to all Aboriginal communities. There are areas where youth suicide is nonexistent, thus a blanket assumption, such as all Aboriginal youth are at an elevated risk, only perpetuates stigmatization. The biomedical focus of mainstream health care and colonial perspective of other services often fail to acknowledge the determinants behind youth suicide within Aboriginal communities. The literature reveals that healthy communities, with low rates of youth suicide, share a common identity, practice cultural continuity and are self-determining. In order to facilitate healthy environments for Aboriginal youth, Canadians must go beyond thinking of health in terms of treating symptoms. We must instead examine and address the historical and contemporary constructions of racism and cultural genocide and work toward developing public policy promoting culturally safe processes.
\end{abstract}

Keywords: youth; suicide; cultural continuity; cultural safety; social determinants; colonialism; self-determination; decolonization; communities; Aboriginal

"I would like to thank Charlotte Reading for the inspiration, support, and encouragement she has provided during my time as a student in the undergraduate program within the school of Public Health and Social Policy. I would also like to thank my fellow online students who generously shared their perspectives and feedback. 


\section{INTRODUCTION}

$\mathrm{I}$

N 2003, Health CANADA identified Aboriginal youth as being fiveto-seven times more likely to commit suicide than non-Aboriginal youth (Kirmayer, 2012). However, this general statistic cannot be applied to all First Nation communities. Many communities within British Columbia reported no suicides in a five year period, while others revealed suicide rates up to 800 times the national average (Chandler \& Lalonde, 1998). The changing demographics in Canada have added an even more critical component to the communities exhibiting high suicide risk. While the general population has nearly doubled in size during the last sixty years, the population of Aboriginal people has become seven times larger (Waldram, Herring \& Young, 2007). Growing numbers of Aboriginal youth and the disproportionate rates of suicide within Aboriginal communities require public policy to promote culturally safe processes, not only in health care, but throughout Canadian society.

This paper examines a select body of literature to provide information on the social, economic and cultural conditions within communities expressing both high and low risk of youth suicide, and to explore the cultural initiatives within Aboriginal communities working to promote the mental wellness of youth. The paper applies findings from the literature to assess the development of public policy aiming to close the gap of health inequity experienced by many Aboriginal people.

\section{LITERATURE REVIEW}

In order to give an overview of the current research on youth suicide in Aboriginal communities, a brief literature review was conducted. Scholarly, peer-reviewed articles published between 2010 and 2014 were electronically searched using search terms related to youth suicide and aboriginal communities, and Canadian public health. The result was 44 articles, which were further narrowed to seven publications by excluding those discussing urban environments and/or 
focusing on issues other than youth and mental wellness.

The selected literature gives a variety of factors and conditions contributing to a high risk of youth suicide in Aboriginal communities. These range from systemic issues such as historical events and colonial processes, to specific behaviours such as substance use and domestic violence (Tousignant, 2013). Tousignant notes that suicide is the "result of interaction between the psychobiological factors and contemporary stress" (p. 401). Thus, a discussion on youth suicide requires a broad perspective in order to unravel the multiple and complex roots explaining the differential levels of suicide risk within Aboriginal communities (Wesley-Esquimaux \& Snowball, 2013).

Additional factors related to youth suicide noted in the literature include the intergenerational trauma stemming from residential school experiences, overcrowded housing, and unresolved crime (Tousignant, 2013). Authors Finley, Morris, Hardy and Nagy (2010) mention various social determinants that influence the wellbeing of youth, such as early life experiences, education, employment, working conditions, food security and social exclusion. Another article suggests that the mental wellness of Aboriginal youth is associated with identity and colonization, where current programs and services failed to "instill a sense of native pride" for Aboriginal participants (Lavalee \& Poole, 2010).

Several implications for public health practice and policy development were also discussed within the literature. Webster (2012) notes that current suicide prevention strategies within Aboriginal communities are substandard because of a lack government funding to promote culturally relevant research and sufficient community data. Another article suggests the "urgent need to increase the number of evaluations of preventative interventions" (Clifford, Doron \& Tsey, 2013, n.p.) by using solid research designs to create evidence-based, culturally relevant programs (Clifford, Doron \& Tsey, 2013). However, three articles selected in the literature review note that the specific concepts of culture promoting health must be defined by Aboriginal communities in order to promote "cultural authenticity" within programs (Nygard, 2012; Webster, 2012; Clifford, Doron \& Tsey, 2013). 
1. The determinants underlying differential rates of aboriginal youth suicide

The Royal Commission on Aboriginal Peoples states that children, "according to tradition....are gifts from the spirit world and must be treated well or they will return to that realm" (First Nations, 2007, p. 7). Yet, out of all the groups in the world identifiable by culture, Aboriginal youth in Canada are the most likely to take their own lives (Chandler, Lalonde, Sokol \& Hallet, 2003). Why, despite being considered a gift in Aboriginal culture, are so many youth choosing to die? The answer lies in the historical and contemporary determinants influencing the lives of Aboriginal people.

\subsection{Socio-economic determinants}

Many determinants of suicide, expressed in communities with high risk, are socio-economic in nature. On average, Aboriginal suicide victims are younger than non-Aboriginals who take their own lives and are more likely to be using alcohol at the time of death (Waldram, Herring \& Young, 2007). The use of alcohol and other substances can be seen as a measure of coping with feelings of hopelessness and inadequacy (Waldram, Herring \& Young, 2007). Waldram, Herring and Young (2007) identify four risk factors for substance which include parental and sibling role modeling, cultural stress, lack of social support and learned helplessness.

Former Chief of the Assembly of First Nations, Phil Fontaine, states despite Canada being a wealthy nation, "First Nations endure poverty and third world conditions in their own home land" (First Nations, 2007, p.26). In 2001, a census identified Aboriginal youth living in families as more than twice as likely to live in poverty as non-Aboriginal youth (First Nations, 2007). In the same year, the First Nations Regional Longitudinal Health Survey reported that the median annual income of households on reserve, with children, was less than half of the Canadian median income. Housing, water supply and sewage control is often sub-standard in First Nations communities (Waldram, Herring \& Young, 2007). Levels of literacy and edu- 
cation are also far below average (First Nations, 2007). Furthermore, since "there are few job or training opportunities available to Aboriginal youth, on reserve or off, they are left with little choice" (First Nations, 2007, p. 29) but to adopt often harmful coping strategies (First Nations, 2007).

The mainstream marginalization of Aboriginal status can compound other sources of stress (MacNeil, 2008). Life in high risk communities has been shown to include family dysfunction, loss of cultural beliefs, and the inability to meet basic needs or attain the skills to do so, allowing feelings of low self-esteem and hopelessness to develop (MacNeil, 2008). When a suicide does occur within a community, the risk becomes higher for other youth, since a chain reaction can result. Imitating the act becomes an option if they "identify with the victim, blame themselves, and believe they are meant to be the next victim" (p.8).

\subsection{Historical determinants}

Historical factors continue to play a role in the mental health and rates of suicide among Aboriginal youth. Destructive colonial practices strived to assimilate Indigenous peoples, causing trauma and disconnection from traditional beliefs and cultures. Residential schools removed children from their families, communities were dislocated from traditional territories and the expression of culture was forbidden (White \& Jacobs, 1992). In Historic Trauma and Aboriginal Healing, Wesley-Equimaux and Smolewski (2004) describe the effects of colonialism on youth today. They present the idea that "residue of unresolved, historic, traumatic experiences and generational or unresolved grief is not only being passed down from generation to generation, it is continuously being acted out and recreated in contemporary Aboriginal culture" (p. 3). Evidence to this claim lies in the social problems of communities with a high rate of youth suicide. Social scientists have also noted the prevalence of substance, domestic, and sexual abuse "is largely from the destruction of Indigenous culture" (MacDonald, 2009, p. 177). 


\subsection{Political determinants}

Western-based political ideology and policies of past and present have an oppressive effect on Aboriginal youth and are a factor in creating the sense of hopelessness known to be present before a youth commits suicide (MacDonald, 2009). The control held by the Canadian state over Aboriginal affairs, such as resources and services, can be traced as the main reason Aboriginal youth are over-represented in Canada's child welfare system (MacDonald, 2009).

Despite the closing of residential schools, many children continue to be removed from their homes and placed in care because of perceived neglect (Blackstock, 2011). However, in most cases, basic needs of Aboriginal children are unmet because of "political factors such as gaps in jurisdictional accountability, and at times, a lack of due process in family courts" (MacDonald, 2009, p. 178). In a CBC interview, Cindy Blackstock (2011) expresses policy, which sets Aboriginal families up for failure, is the reason children are put into care by child welfare workers. Instead of removing children and causing further trauma to families, the state needs to address underlying issues, such as addiction, poverty, unemployment, literacy, and education (Blackstock, 2011).

Currently, Canada participates in the unjust practice of blaming Aboriginal parents for the inadequate care of their children, without addressing the policies that are the cause of the neglect (Blackstock, 2011). In cases where youth are not placed in care when families are unable to provide, they may be left with little option but to rely on crime in order to meet food and shelter needs, partly explaining the disproportionate rates of Aboriginal youth in the correctional system (National, 2007).

\section{Determinants in communities with low suicide risk}

\subsection{Cultural continuity}

As previously mentioned, the prevalence of youth suicide is not a concern in every Aboriginal community (Chandler \& Lalonde, 1998). 
In their article, Chandler and Lalonde (1998) reveal the presence of cultural continuity protects youth by facilitating a healthy transition from adolescence to adulthood. Continuity in a community is defined as the process of cultural rehabilitation or the attempt to reconstruct traditional practices. A community's effort to re-establish culture anchors youth to a positive vision of themselves in the future (Chandler \& Lalonde, 1998).

Chandler, Lalonde, Sokol and Hallet (2003) describe the presence of six markers of cultural continuity as creating a healthy environment for youth. Their study correlates the low incidence of suicide in a community with the following markers: the effort to secure land claims, the success in attaining a degree of self-government (political and economic independence), band-administered schools, community owned or controlled fire and police services, band and tribal councils having control of health services, and the existence of a facility constructed for the sole purpose of hosting cultural activities. In such communities, youth experience an opportunity to contribute to cultural preservation, develop a positive identity and be in control of their future and destiny (Chandler et al., 2003).

In order to provide a more detailed explanation of the concept of cultural continuity, a few of the ground-level activities taking place within the markers are identified. In the article "Aboriginal language, knowledge and youth suicide," Hallet, Chandler and Lalonde (2007) report that the rate of suicide disappears in communities where more than half of the members have knowledge of a traditional language. The authors define language as the most important method of cultural continuity because it expresses "another way of looking at the world, of explaining the unknown and making sense of life" (Battiste, as cited in Hallet et al., 2007, para. 3). Ceremonies are also important for the continuation of culture. They are known to facilitate the "discharge of emotion... and provide powerful group empathy and cohesion which reinforce(s) the social self-image of each individual participant" (Hart, 2002, p. 59). Elders are central figures for facilitating the cultural transmission in Aboriginal communities by providing guidance, counselling and performing ceremonies (Hart, 2002, p. 58). Tra- 
ditional activities, such as hand-drumming, have also been proven to empower people to take control over their health in a holistic manner by incorporating physical, mental, spiritual and emotional aspects of wellness (Goudreau et al., 2008).

\subsection{Self-determination}

As Chander and Lalonde (1998) note, self-determination, where a population group has political freedom to guide their own course of action, is closely related with cultural continuity. Self-determination is accomplished when a community establishes a cohesive identity, gains control and is accountable for political, economic and social structures that affect the members (Reading, 2012). Chandler et al. (2003) report low suicide rates within Aboriginal communities having achieved a degree of self-determination. However, such an achievement requires strong leadership, support from the community and appropriate support from non-Aboriginal groups (Reading, 2012). Variations of these requirements exist in each community and acquiring them can be difficult and take time (Reading, 2012). Nevertheless, when public policy fails to promote self-determination and instead focuses on specific issues such as housing or education, significant long-term change is unlikely (Reading, 2012).

\section{Public policy to reduce suicide risk}

Cultural continuity, tied with a degree of self-determination, is proven to provide Aboriginal youth with a healthy environment and decrease the impact of socio-economic, political and historical factors influencing the risk of suicide (Chandler et al., 2003). However, not all communities have an opportunity to achieve such measures. Cultural continuity and self-determination are not equally attainable, as each community experiences different impacts, obstacles and levels of oppression. Therefore, rather than developing policy based on statistics, which may create blame and further oppress communities, policy must be shaped to ensure all youth have the opportunity to experience themselves as continuous in time (Chandler et al., 2003). In 
order to support communities in establishing healthy environments for youth, cultural safety must be embedded within public policy.

\subsection{Defining cultural safety}

The term "cultural safety" originated in New Zealand to address the inequitable health outcomes experienced by Maori people after receiving culturally inappropriate and insensitive care (De \& Richardson, 2007). The process begins with self-reflective exercises promoting a deeper sense of awareness, where individuals examine their beliefs, social position in the world and how they relate to others. De and Richardson (2007) note the way "not everyone believes or does exactly the same thing" (para. 20). Thus, if we are consumed by our personal perspectives, we "risk inadvertently stereotyping people by putting together lists of what we think people do or believe based on assumptions, myths and stereotypes" (De \& Richardson, 2007, para. 20). Applying cultural safety to public policy has potential to promote respectful relations among diverse groups, which will go much farther in promoting health than if cultural safety is limited to interactions within health care (De \& Richardson, 2007).

Viewing Aboriginal youth suicide through a culturally safe lens highlights much of the hopelessness leading to the loss of life as being rooted in structural and institutional racism within medical, educational and economic systems. For instance, Western medicine disregarded traditional practices during European settlement (White \& Jacobs, 1992). After Aboriginal healing practices failed to help people regain health, traditional medicine was further stigmatized and labelled inadequate (White \& Jacobs, 1992). Since religion and culture are part of Aboriginal medicine, they too, were disregarded (Waldram, Herring \& Young, 2007). Residential schools split up families and encouraged children to "despise in themselves all those things which were essential to their identity" (White \& Jacobs, 1992, p. 19). Exclusion from the economy was enacted by the state in the form of laws. Land was confiscated, resources were denied and Aboriginal people starved. Chief Seattle said the ways of the white man brought "the end of living and the beginning of survival" (White \& Jacobs, 
1992, p. 127) as traditional perspectives historically held little value for many Euro-Canadians.

\section{Policy implications}

Public policy promoting an advanced level of self-awareness and education on oppression and marginalization is required to hasten social change and allow youth to feel hopeful about the future. Selfdetermination, in the form of communities taking control of resources and services, has been connected to a low risk of youth suicide. Canadians must acknowledge and respect the ability of Aboriginal perspectives to provide the framework for healthy communities. As an example, MacDonald (2009) writes the meaning of autonomy in Aboriginal communities needs to be grounded in traditional culture. Otherwise policy may be shaped by Western-based assumptions regarding political practices, and work to off-load responsibility onto communities while giving no means for adequate funding (Reading, 2012). Such practice will only serve to further oppress communities if inadequate resources and funding are available.

Public policy can facilitate wellbeing for Aboriginal youth by modelling and promoting culturally safe processes and behaviors to all Canadians. For instance, programs and services within every sector need regulations which adhere to cultural safety. Since cultural continuity is established as a central concept in reducing youth suicide risk in a community (Chandler \& Lalonde, 2003), such initiatives need to be valued rather than labelled or stigmatized by the general population. Space that is safe, respectful and appreciative of the many forms of cultural transmission must be created.

Policy makers wishing to aid in the process of establishing cultural continuity need to have knowledge of local perspectives and respect Aboriginal diversity and world views. In her research article, Parent (2011) identifies that when working with Aboriginal youth, policy makers, educators and practitioners must focus on youth interests, strengths, perspectives and historical and contemporary contexts in order to facilitate a healthy outcome. To focus on individual 
deficits is to be blind to the structural and institutional inequalities that exist. Building self-awareness and knowledge of social power imbalances, while staying open to different perspectives and world views, are initial steps toward establishing a level of cultural safety. The Aboriginal concept of the connection between all living things is central to creating supportive environments for youth. The method of acknowledging a sense of interconnectedness, regardless of heritage and cultural differences, will allow everyone to benefit (Barlow \& Reading, 2008).

\section{CONCLUSION}

The alarming frequency of Aboriginal youth suicide in certain communities reflects the unjust nature of Canada's past and present attitudes regarding Aboriginal people. The transition to young adulthood can be an overwhelming experience and the wellbeing of a population is often reflected by the resiliency of the young members. Socio-economic, political and historical determinants of suicide, unique to Aboriginal populations, have been identified as causal factors. Markers of cultural continuity and self-determination have been proven to enable communities to provide healthy, supportive environments for youth. Decision makers must embrace cultural safety theory and embed the practices within public policy. The promotion of self-awareness and education on social the determinants of health will work to relinquish oppressive assumptions and aid in building health equity. 


\section{REFERENCES}

Barlow, J. \& Reading, C. (2008). Relational care: A guide to health care and support for Aboriginal people living with HIV/aids: Final report. Canadian Aboriginal Aids Network. Retrieved from http://www.catie.ca/en/resources/relational-care-guide-healthcare-and-support-aboriginal-people-living-hivaids

Blackstock, C. (2011). Q \& A with Cindy Blackstock. Retrieved from www.cbc.ca/doczone/8thfire/2011/11/cindy-blackstock.html

Chandler, M. \& Lalonde, C. (1998). Cultural continuity as a hedge against suicide in Canada's First Nations. Transcultural Psychiatry, 35(2), 191-219. http://dx.doi.org/10.1177/136346159803500202

Chandler, M., Lalonde, C., Sokol, B., \& Hallet, D. (2003). Personal persistence, identity development and suicide: A study of Native and Non-Native North American adolescents. Monographs of the Society for Research in Child Development, 68(2), 1-130.

Clifford, A., Doron, C. \& Tsey, K. (2013). A systemic review of suicide prevention interventions targeting Indigenous people in Australia, United States, Canada and New Zealand. BMC Public Health, 13(1). np. http://dx.doi.org/10.1186/1471-2458-13-463

De, D. \& Richardson, J. (2008). Cultural safety: An introduction. Paediatric Nursing, 20. 39-44. http://dx.doi.org/10.7748/paed2008.03.20.2.39.c6529

Finlay, J., Hardy, M., Morris, D. \& Nagy, A. (2010). Mamow-Ki-kenda-ma-win: A partnership approach to child, youth, family and community wellbeing. International fournal of Mental Health, 8(2), 245-257. http://dx.doi.org/10.1007/s11469-009-9263-8

Goudreau, G., Weber-Pillwax, C., Cote-Meek, S., Madill, H., \& Wilson, S. (2008). Hand drumming: Health promoting experiences of Aboriginal women from a Northern Ontario Urban Community. fournal of Aboriginal Health, 4(1), 72-83. Hallet, D., Chandler, M., \& Lalonde, C. (2007). Aboriginal language, knowledge and youth suicide. Cognitive Development, 22(3), 392-399. http://dx.doi.org/10.1016/

Hart, M. (2002). Foundations of an Aboriginal approach. In Seeking Mino-Pimatisiwin: An Aboriginal approach to helping (pp. 3959). Halifax, NS: Fernwood Publishing. 
Kirmayer, L. (2012). Changing patterns of suicide among young peo-

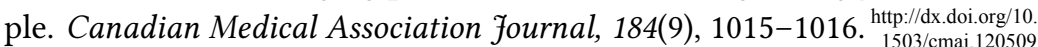

Lavalee, L., \& Poole, J. (2010). Beyond recovery: Colonization, health and healing for Indigenous people in Canada. International fournal of Mental Health and Addiction, 8(2), 271-281. http://dx.doi.org/10.1007/

McIntosh, P. (1990). White privilege: Unpacking the invisible knapsack. Retrieved from http://www.antiracistalliance.com/Un packing.html

MacDonald, F. (2009). The Manitoba government's shift to "autonomous" First Nations child welfare: Empowerment or privatization? In A. Timpson (Ed.), First Nations, first thoughts: The impact of Indigenous thought in Canada (pp. 173-198). Vancouver, BC: UBC Press.

MacNeil, M. (2008). An epidemiologic study of Aboriginal adolescent risk in Canada: The meaning of suicide. Journal of Child and Adolescent Psychiatric Nursing, 21(1), 3-12. http://dx.doi.org/10.1111/j.

National Council of Welfare Reports. (2007) First Nations, Metis and Inuit children and youth: Time to act (Cat. No. HS54-1/2007E). Ottawa, ON: National Council of Welfare.

Nygard, A. (2012). Cultural authenticity and recovery maintenance in a rural First Nation community. International fournal of Mental Health and Addiction, 10(2), 162-173. http://dx.doi.org/10.1007/s11469-011-9317-6

Parent, A. 2011. Keep us coming back for more: Urban Aboriginal youth speak about wholistic education. Canadian fournal of Education, 34(1), 28-48.

Reading, C. (2012). Self-determination [powerpoint slides]. Lecture Notes.

Tousignant, M., Vitenti, L. \& Morin, N. (2013). Aboriginal youth suicide in Quebec: The contribution of public policy for prevention.

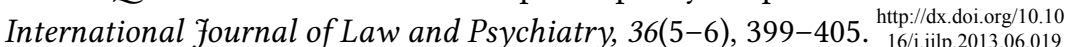

Waldram, J., Herring, D. \& Young, T. (2007). Aboriginal health in Canada: Historical, cultural, and epidemiological perspectives.

Toronto, ON: University of Toronto Press.

Webster, P. ( 2012). Aboriginal health programming under siege, critics charge. Canadian Medical Association fournal, 184(14), E739- 
E740. Retrieved from http://search.proquest.com.ezproxy.library. uvic.ca/docview/1314476453?accountid=14846 http://dx.doi.org/10.1503/cmaj.109-4282

Wesley-Equimaux, C., \& Smolewski, M. (2004). Historic trauma and Aboriginal healing. Ottawa ON: Aboriginal Healing Foundation. Retrieved from http://ezproxy.library.uvic.ca/login?url=http://site. ebrary.com/lib/uvic/Doc?id=10078906

Wesley-Esquimaux, C., \& Snowball, A. (2010). Viewing violence, mental illness and addiction through a wise practice lens. Interna-

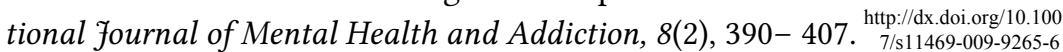
White, L. \& Jacobs, E. (1992). First Nations Law: A wholistic approach to extended families. In Liberating our children, liberating our nations (pp. 5-25, 125-127). Victoria, BC: Community Panel and Family and Children Services. 